\title{
LETTERS
}

\section{Poverty as a medical condition}

In a welcome CMAJ editorial, Dr. Patrick and colleagues ${ }^{1}$ announced that "vulnerable populations" is to be a continuing thematic focus of the journal. We wish to draw attention to one important cause of vulnerability - poverty - and how a focus on poverty and other social determinants could herald a salient shift in our model of disease and research for the journal and for medicine more broadly.

CMAJ's mission, as stated by Patrick and colleagues, is to "champion knowledge that matters for the health of Canadians," including "high-quality evidence and analysis." Traditionally, medical evidence and analysis have been oriented around diseases, from basic research on the biology of disease and clinical epidemiological research on disease screening and intervention to disease-specific clinical guidelines. This orientation is consistent with a medical model that still places biomedical diseases at the centre. ${ }^{2}$ Although G.L. Engel's rival biopsychosocial model was once touted in the pages of major journals, ${ }^{3}$ it has been somewhat displaced by newer humanistic movements like narrative medicine and person-centred medicine.

The subtle ambitiousness of Engel's proposal may be underappreciated. Engel argued not only for accepting psychological and social factors as distant upstream "social determinants" but also for widening the borders of disease to permit these entities. Applying this model to poverty could mean recognizing poverty as a medical condition for which we can screen with validated questions, that has causes, that is a risk factor for other conditions (including chronic diseases), that we can diagnose and that we can treat with available resources. ${ }^{4}$

Although the field of social epidemiology has studied social ills like poverty for some time, managing poverty will require high-quality evidence from clinical epidemiology as well. It will also require highquality, evidence-informed guidance. To this end, the Centre for Effective Practice has produced a tool for frontline clinicians in Canada to help them screen for, identify and intervene in poverty. ${ }^{4}$

Producing knowledge that matters for the health of Canada's vulnerable populations may require no less than reorienting medical research and guidelines.

\section{Jonathan Fuller PhD}

Medical student, University of Toronto, Toronto, Ont.

\section{Mayura Loganathan MD}

Family physician, University of Toronto, Toronto, Ont.

Cite as: CMAJ 2018 August 27;190:E1022. doi: $10.1503 / \mathrm{cmaj} .69637$

\section{References}

1. Patrick K, Flegel K, Stanbrook MB. Vulnerable populations: an area CMAJ will continue to champion. CMAJ 2018;190:E307.

2. Fuller J. The new medical model: a renewed challenge for biomedicine. CMAJ 2017; 189:E640-1.

3. Engel GL. The need for a new medical model: a challenge for biomedicine. Science 1977; 196:129-36.

4. Poverty. Toronto: Centre for Effective Practice/ The Well. Available: https://thewellhealth.ca/ poverty\#tools (accessed 2018 Apr. 4).

Competing interests: None declared. 